\title{
NEGRITUDE E PROTAGONISMO: UM PEIXEFRITANO MODO DE SER E ESTAR NO OLHO DO FURACÃO DA PROVÍNCIA
}

Paulo NUNES

Vânia Torres COSTA

\begin{abstract}
RESUMO
Este ensaio parte da denominação do grupo de intelectuais- Academia do Peixe Frito- para enfatizar o papel por ele exercido nas ações modernizantes- negritude e vozes periféricas - de Belém na primeira metade do século XX. Nome e ação que marcam irreversivelmente, portanto, nosso modo de ser e estar na Amazônia.
\end{abstract}

Palavras-chave: Academia do Peixe Frito. Modernismo. Renovação.

\section{RESUMEN}

Este ensayo parte de la denominación del grupo de intelectuales-Academia del Pez Frito-para enfatizar el papel por él ejercido en las acciones modernizantes-negritud y voces periféricas - de Belém en la primera mitad del siglo XX. Nombre y acción que marcan irreversiblemente, por lo tanto, nuestro modo de ser y estar en la Amazonia.

Palabras-clave: Academia del Pez Frito. Modernismo. Renovación.

\section{ABSTRACT}

This essay is part of the denomination of the group of intellectuals - Fray Fish Academy - to emphasize the role it played in the modernizing actions - blackness and peripheral voices - of Bethlehem in the first half of the twentieth century. Name and action that irreversibly mark, therefore, our way of being and being in the Amazon.

Keywords: Fried Fish Academy. Modernism. Renovation.

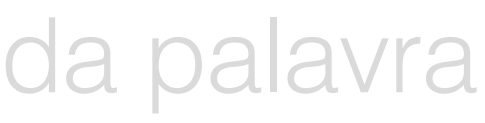


Não, não procure a ata da primeira ou da última reunião. Lista de frequência? Não há. Que pistas podemos, leitores-detetives que somos, obter de sua existência fecunda, lúdica e controversa? De certo, há rastros dela nos textos criados por seus integrantes. Sim, podemos começar a nos entender a partir da leitura de reportagens, resenhas, prefácios, poemas, crônicas, romances, entrevistas... eles dão o tom da negritude, da indianidade, da 'caboquice' das gentes dos arrabaldes, das ilhargas da cidade, da 'criaturada dos pés no chão'. Uma ânsia de renovar, evidenciar o protagonismo dos "deserdados pelo poder" que, efetivamente, desestruturou o mofado provincianismo belemense. Eles, peixefrianos, deixaram rastros fisionômicos nos chãos de Belém, nos paralelepípedos e nos trapiches da Cidade Velha, nos chãos da Campina, do Reducto, do Jurunas, do Umarizal, da Vila da Barca, do Telégrafo, da Cremação... Eis o entroncamento entrançado ruas, vielas e becos que a nós apresenta a Academia do Peixe Frito.

Poucas instituições literário-culturais foram tão despretensiosas e ao mesmo tempo tão decisivas para a republicanidade do Pará - e para a vida sociocultural de Belém - que a Academia do Peixe Frito (APF). Em tempo, Jaques Flores é elucidativo:

Quem se der ao gosto de fazer uma ligeira observação sobre a vida literária local, de certo vê deslizar à sua frente numerosas associaç es fundadas, especialmente para movimentar as belas letras de Belém (...) Dessas associações, duas podem ser classificadas como as que melhor hajam correspondido à finalidade para que foram organizadas; a Mina Literária e a Associação dos Novos (1990: 59).

Flores ressalta a palavra organização, que dá substancialidade a um projeto, mesmo que informal, a essa agremiação de que ele ativamente participou e por isto ele trata com propriedade. O grupo, então chamado de Associação dos Novos, engendrou uma espécie de cordame de ações que se estendeu dos anos 30 do século XX (embora, antes, como 'Vândalos do Apocalipse' eles já 'aprontassem') até a década de 50 dos XX. Fruto de uma atuação lúdica e de insurreição classe, a Academia do Peixe Frito (atualização nominativa da Academia dos Novos) é fruto consistente de um 'espirito do tempo' da geração de Bruno de Menezes; companheiros na vida política, de jornada na literatura, enfim, no jornalismo, eles demarcaram, com suas atuações por meio dos livros e nas redações dos jornais, novas formas de atuar no cotidiano de Belém, palco de movimentação desses atores sociais de brilho inconteste e obra instigante e propositiva.

Dedicatórias trocadas entre Dalcídio (D) e Bruno (E): um renga de louvor à $\mathrm{APF}$ ?

VOL. 15 | N.1 | JUL. 2018 ISSN 1415-7950
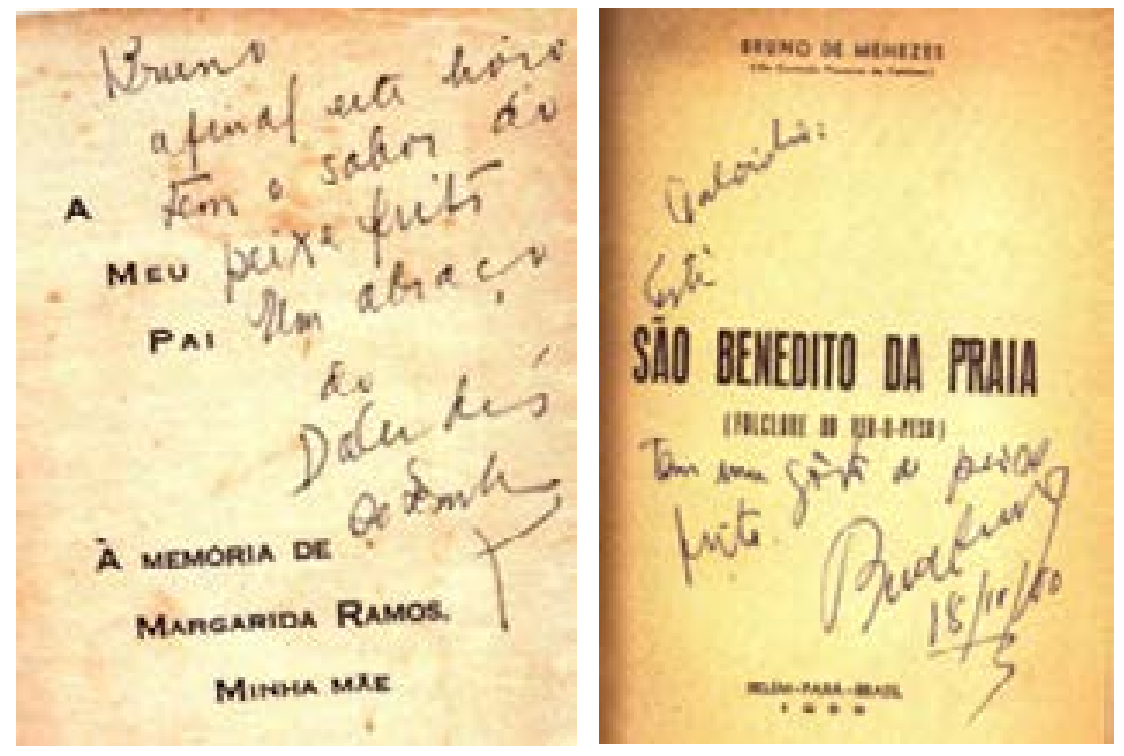
Se isto é verdade, verdade é também que, efetivamente, demoramos muito tempo para reconhecer a importância da Academia como grupo propositivo e geração atuante, e, mais que isto, decisiva. Deste modo - é preciso fazer uma autocrítica - menosprezamos por muito tempo a ação dinamizadora, consequente e consciente da APF, como se a geração de Bruno de Menezes, primeiro poeta-paradigma de nossa literatura moderna (e modernista), não estivesse ciente de sua movimentAÇÃO como grupo que propunha mudanças nos padrões estéticos, socioculturais e políticos que superassem a estética tradicionalista e, deste modo, nos tirassem da mesmice reinante naqueles dias.

A Academia do Peixe Frito, pouco a pouco, transformou-se em um grupo que possibilitou a democratização de oportunidades para os que habitavam nos arrabaldes de nossa cidade, fugindo da "geografia de oportunidades" de uma elite social, econômica e política, seringalistas e/ou comerciantes, elite privilegiada (por vezes branca ou embranquecida) da Belle Époque. Assim, diferentemente à tendência do silêncio reinante, é necessário que reconheçamos estudiosos que chegaram até nós e nos antecederam - pesquisando temáticas, geralmente ligadas às inovações estéticas e da Negritude - e assim nos abriram os olhos para a importância da Academia do Peixe Frito: Vicente Salles, José Varela Pereira, Aldrin Moura de Figueredo, Luiz Augusto Pinheiro Leal, Maíra Maia, Marinilce Coelho, Lenora de Menezes Brito, Salomão Laredo, Salomão Habib ${ }^{1}$, os mais lúcidos e consequentes em se tratando deste momento fundamental de nossa modernidade, daí porque somos devedores a eles, e registramos aqui nossa gratidão.

A Academia do Peixe Frito, não esqueçamos, tinha muito a fazer para dar visibilidade às vozes dos "margens"; afinal, Belém acabara de vivenciar a higienização europeizante, advinda do projeto elitista da Era da Borracha/Belle Époque, viabilizado sobretudo pela figura política de Antônio Lemos. Durante o referido período, que paira sobre nossas cabeças como um fantasma beligerante, a capital do Pará, cidade de "cabocos", teve de vestir espartilhos e chapéus de "madamas", bem como enfeitar-se com as polainas e bengalas dos "monsieures" a ostentar trajes de linho HJ. E num contexto elíptico, em que o dinheiro esboroara-se devido à desvalorização da hevea brasiliensis no mercado internacional, Bruno de Menezes, motor de popa dessa história cultural, percebera a oportunidade de abrir e sedimentar espaços para que novos personagens advindos das "beiradas" da cidade (os arrabaldes de Belém) tivessem vez e voz em nosso mundo sociocultural; não bastava mais apenas reresentar seus contemporâneos, figurando-os como os pais Joões, os Pés de Bola capoeiristas, as Ambrosinas e as Mães Pretas, que desfilariam nas páginas dos livros (o que por si só já configura um enorme alargamento de horizontes para questionar o cânone europeu de nossa cultura); era preciso, mais do que nunca, reunir também a rapaziada que militava nos movimentos populares, e que sobrevivia com dificuldades para "ganhar o pão" de cada dia.

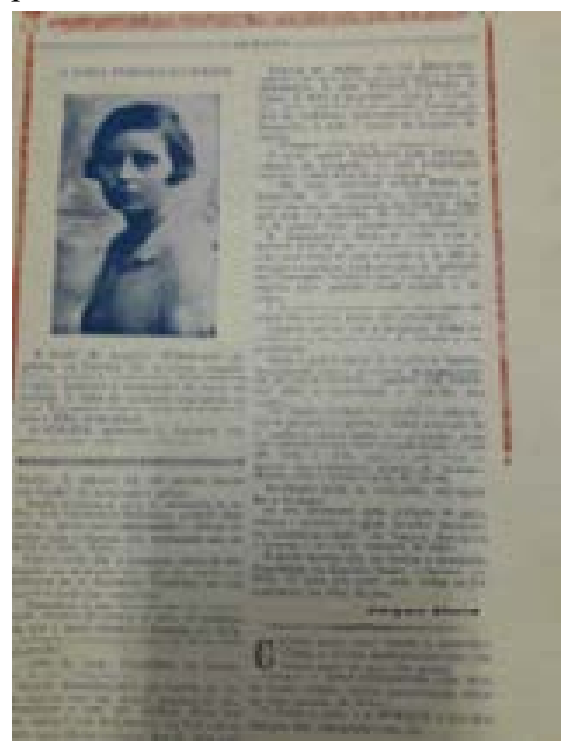

Jaques Flores escreve para A Semana, uma das revistas que prepara o terreno para as renovações culturais por vir
1 Vale destacar a bela pesquisa do compositor-violonista Salomão Habib sobre Tó Teixeira, que desaguo numa bela publicação pela editora do SESC, de São Paulo, com o sugestivo título de Tó Teixeira, o poeta do violão, em 2013, reúne trajetória biográfica, livro de partituras, CD e DVD com peças do "tio Tó". 
Não é demais lembrar que a geração de Bruno já tinha, antes, estabelecido diálogo para além das fronteiras da Amazônia, principalmente com os modernistas pernambucanos, (não do grupo hoje mais conhecido: o de Gilberto Freyre, mas o outro, "mais operário", o de Joaquim Inojosa), conforme atestam as cartas e textos do próprio Inojosa, publicados em diversos livros e revistas. É fato também que Raul Bopp já havia circulado nas rodadas de debates e encontros dos cafés à parisiense que se localizavam no centro de Belém; eram atentos ouvidos gaúchos a escutar a dicção dos Vândalos do Apocalipse. Ainda neste campo de circulação de ações modernizantes, lembramos que Mário de Andrade em 1927 tinha prospectado a "cidade do Pará" e, num jeito talvez esnobe (premeditado ou não), ignorado os que aqui produziam arte e cultura, o que certamente não será perdoado pelo peixefritano mais intenso e aguerrido, Abguar Bastos que não deixará de ridicularizar a figura do 'poeta paulista ilustre'. No campo dos lançamentos literários ${ }^{2}$, já tinham saído do prelo Bailado Lunar (1924), Batuque (1930-1), de autoria de Bruno de Menezes. Era, portanto, necessário avançar. E o avanço deu-se pela via do contato lúdico, do engajamento lúcido, boêmio, mas também, e sobretudo, através de proposições daquilo que de modificador os peixefritanos passaram a praticar, seja no jornalismo, seja na ação política não institucional, seja nas noitadas de serenata e visita aos barracões de bumbás, pássaros e terreiros de Umbanda, de que participavam Tó Teixeira, Bruno de Menezes, Jaques Flores, De Campos Ribeiro, Gentil Puget, Raymundo Vianna, dentre outros.

Antes, no entanto, de avançarmos na sagração da ação da APF, é necessário refletirmos sobre o nome do grupo, pois, na reapropriação do que propusera Ana Maria Machado ${ }^{3}$, em O Recado do Nome (1976), os nomes próprios são eficientes indicativos das potencialidades que eles sustentam em dado enredo da história ou da História. A expressão Academia do Peixe Frito - aqui usada de modo irônico estrutura-se a partir de dois universos semânticos aparentemente opostos: Academia + Peixe Frito. Academia denota a formalidade e uma agregação elitista e, por vezes, conservadora; guardiã da tradição e do tradicionalismo; as academias, sobretudo as de Letras (a do Brasil é inspirada na Academia Francesa), reúnem, em geral, nomes canônicos (embora isto possa ser questionado em casos bem pontuais). "peixe frito", por sua vez, é expressão que estaria no outro extremo socioeconômico da significação aglutinadora, pois ela aponta para o viés popular, marca da alimentação que caiu no gosto dos não abastados e que a partir daí contagiou as classes médias de Belém. Para se saber mais dos atravessamentos sociais do peixe frito como preferência alimentar, faz-se necessário conhecer o que escreve Jaques Flores na crônica "Vamos comer Peixe Frito?", inserida na antologia Panela de Barro (1947), donde se pode ler:

2 Não nos ocuparemos das revistas e suplementos literários, o que já feito por pesquisadores como Marinilce Coelho, Julia Maués e Aldrin Moura de Figueredo, dentre outros.

3 Embora Ana Maria Machado se ocupe do nome dos personagens de Guimarães Rosa, cremos na validade de um poder adâmico, força expressiva, social e simbólica advinda das nomenclaturas.
[Para comer peixe frito] (...) não aparecia só gente de pé no chão e camisa de meia ou blusa suja não! Vi muitos camaradas de gravata, desses metidos a sebo, comprando as suas postas, naturalmente para melhorar o almoço ou mesmo para constituir o dito (FLORES, 1990: 155).

O peixe frito passará, então, a cair no gosto também dos de "gravata, metidos a sebo", como ressalta Flores em sua crônica que é verdadeiro documento sociológico.

Ainda perseguindo a denominação do grupo, vale lembrar que este emblemático nominativo - Academia do Peixe Frito - sedimentou-se, cristalizou-se a posteriori, uma vez que, antes, registros dão conta de que eles, os acadêmicos peixefritanos, se auto identificavam, como referido aqui anteriormente, como "Academia dos Novos", daí percebermos a caracterização de comportamento inovador, conforme aponta documento de De Campos Ribeiro, datiloscópia que nos foi cedida pela família do autor: 
Lenora de Menezes Brito ${ }^{4}$, no entanto, defende outra versão. Segundo ela, o nome Peixe Frito foi escolhido nas imbricações cotidianas dos nossos modernistas na região central de Belém, mais especificamente no conglomerado comercial no entrono da balança de "haver o peso", hoje Ver-O-Peso, o mais emblemático monumento da cidade de Belém. Diz-nos a professora e pesquisadora, em depoimento elucidativo para Gallindo:

O Ver-O-Peso é um verdadeiro viveiro humano, lá a miscigenação está presente. Temos negros, descendentes de negros, de indios. Temos as cores maravilhosas das velas, dos barcos. Temos os odores das frutas, das comidas e do peixe frito... E este grupo também conversando com os caboclos nas canoas, resolveu... "o nosso nome vai ser 'Grupo do Peixe Frito'...".

O negro já do terreiro, do quintal, já mestiçado, trabalhado por Gentil Puget, e o negro do ritual, trabalhado por Jaime Ovalle, surgira, com certeza, já daquelas pesquisas do trabalho pioneiro da literatura no Pará [referência feita ao grupo liderado por seu pai, Bruno]. Isto é uma tese que defendemos: sem os primeiros literatos no Pará, sem aquela onda de renovação da literatura no Pará, é possivel que a renovação da música no Pará não tivesse ocorrido.

Lenora Brito, desta feita, interliga música à literatura, destacando a tendência de músicos e poetas beberem nas fontes da hibridação cultural do Ver-O-Peso. A pesquisadora não somente conhece sobre o assunto, como vivenciou, mesmo à distância, as andanças de seu pai e seus camaradas no cotidiano do mercado que é, por assim dizer, o entrelugar ${ }^{5}$ da cidade com o rio, do paralelepípedo com o barro, advindo das águas da bacia amazônica. Lugar de várias tonalidades, etnias e sotaques, o Ver-O-Peso representa aquilo a que os peixefritanos desejam encarnar, o que desagua numa preamar de ações proeminentes, quando Bruno de Menezes, por exemplo, pesquisa e escreve sobre São Benedito da Praia: devoção do santo preto, acontecida no bar Águia de Ouro, espécie de altar sacrossanto para as manifestações polifônicas da APF.

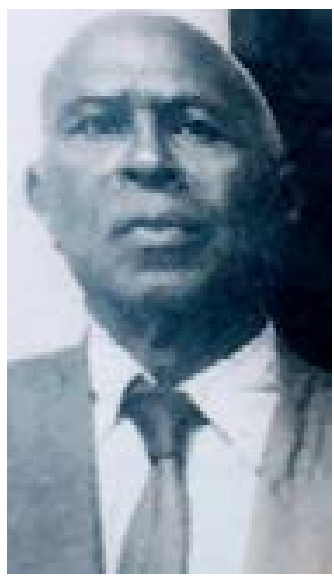

Tó Teixeira, fundamental no processo de modernização de nossa cultura. (Acervo Salomão Habib).

Mas ainda em consideração ao nome da agremiação, as versões por nós levantadas não param por aí. Dalcídio Jurandir dá a sua contribuição para chegarmos a uma 'conclusão inconclusa'. Aparentemente sem pretensões de batizar esta geração, ele dá o seu testemunho nos preâmbulos ${ }^{6}$ de sua obra prima, o romance Chove nos Campos de Cachoeira, edição de 1941, da Vecchi:

... É notável a influência do peixe frito na literatura paraense! Peixe frito é o peixe vendido em postas nos tabuleiros do Ver-O-Peso, ao lado do mercado de Belém. É a comida para quem não deixa almoço comprado em casa. Ao chegar ao meio dia, o pobre se tem a felicidade de ter arranjado dois mil réis leva um embrulhinho envergonhado de peixe para casa. A vida literária do Pará tem se movimentado em torno do peixe frito. Conheço profundamente esse drama. Sempre fui empregadinho público como me chamou um certo imortal (da Acade-
4 Professora, musicista, mestre em musicologia, Lenora é filha do poeta Bruno de Menezes, e escreveu dissertação que defende o movimento de Negritude entre os música do Pará na primeira metade do século XX. A professora participa de alguns documentários sobre o assunto, dentre eles está este de onde retiramos este testemunho. In: GALLINDO, Afonso. O Negro no Pará: 50 anos depois. Vídeo documentário, dirigido por Afonso Gallindo, Belém, Instituto de Artes do Pará, 2005.

5 O conceito de entrelugar aqui se associa à ideia de espaço profícuo de convivência de contrários e diversos. O Ver-O-Peso configura estes entremeio de diversidade em convivências. 
mia de Letras do Pará), morando numa barraca em São João, com a família e perseguido pelos camisas verdes. Acabei gramando xadrez comum, onde os ladrões de galinha e porristas ficavam vinte e quatro horas (...) Me ficava bem, aliás, estar em companhia daquela pobre gente, em vez de estar em companhia dos autores da infâmia (...) A vida do intelectual na província é mais trágica do que se pensa (...) $O$ resto é o peixe frito (Jurandir, IX, 1941).

"A vida literária do Pará tem se movimentado em torno do peixe frito", afirma Dalcídio. O depoimento testemunhal do autor de Marajó equivale a um soco do estômago. Valeria até perguntar o que mudou de lá para cá em relação ao tratamento dado pelo Estado aos seus intelectuais. Pouco, muito pouco parece ter se modificado. Mas voltemos ao nosso foco de interesse; percebe-se que o romancista marajoara fala de "dentro para fora", da experiência de um intelectual que gramou "na província", misérias humanas, sobretudo quando foi perseguido por motivos político-ideológicos. Curioso é o fato de que o depoimento do ilustre romancista encontrar similitude (no que diz respeito à preferência popular do peixe como opção alimentícia dos pobres), no poema, escrito, setenta e poucos anos mais tarde, por Marília Tereza Menezes $^{7}$, poeta e religiosa, como veremos adiante:

Eu recordo, meu pai, quando tu vinhas suado, extenuado,

o paletó no braço, gravata solta ao vento da baía, ao sol do meio dia

E me dizias, ao ver-me preocupada: "Cheguei da Academia". - A essa hora, papai? mas que Academia?

- "Ora, do Peixe Frito, minha filha:

É lá no Ver-o-Peso:

Encontro de poetas, de escritores..."

Nada compreendi, e ele me disse:

"Mas pensei em vocês. Eis o que trouxe

Para ajudar no almoço".

E ali na mesa, acalmando a mamãe, abriu um embrulhinho: Eram postas de peixe, bem fritinho.

Quitute mais gostoso não havia, com a farinha,

Para gente faminta

6 Observe-se anteriormente a dedicatória do romancista a seu amigo Bruno de Menezes, destacada neste artigo.

7 Filha do poeta Bruno de Menezes, a única que pratica, atravessada por sua vida de missionária católica, a literatura herdada do pai.

\section{asas}

da palavra
VOL. 15 | N. 1 ISSN $1415-7950$

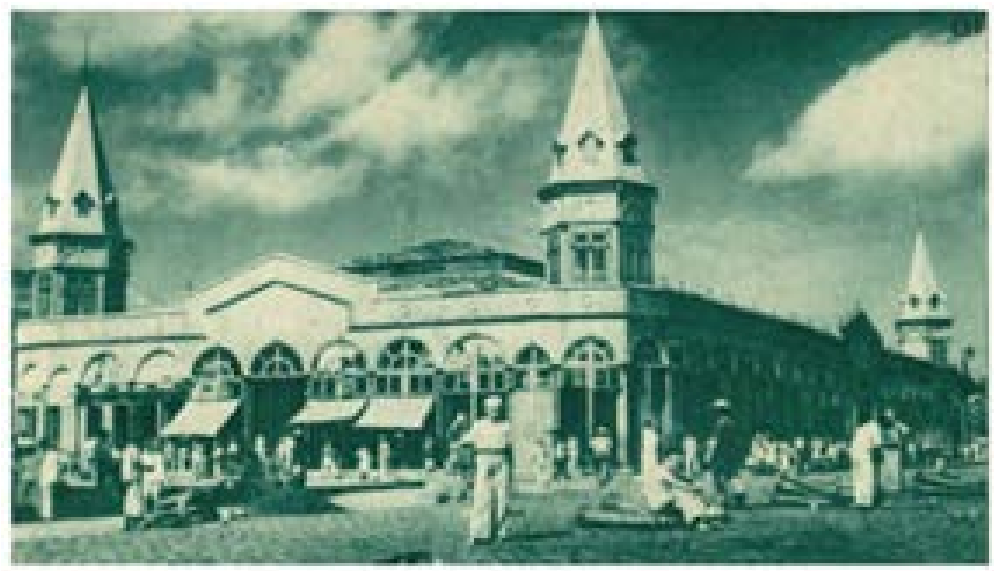

Como Associação dos Novos, Grupo do Peixe Frito ou Academia do Peixe Frito, tanto faz, o que percebemos é uma agremiação lúdico-boêmia e efetiva no que tange às lutas pelos direitos civis, da diversidade etnicocultural dos que viam necessidade de renovar os costumes e a arte na Belém da primeira metade do século XX; agrupamento que lutou para viabilizar os cultos religiosos dos terreiros e demais tra- 
ços das culturas diaspóricas dos afrodescendentes ou dos afroindigenas e caboclos. Assim é que podemos afirmar que não foi à toa que o nosso grupo de estudos optou por assumir para si a última denominação - Academia do Peixe Frito - porque ela encarna toda a plurissignificação e a 'ironia reciclável' dos que, sem rebelar-se sectariamente contra o passado (é bom lembrar que Bruno iniciou sua trajetória literária como parnasiano-simbolista, por isto era um grande sonetista: agitador cultural que não se negava a frequentar os cafés dos moços chiques), apostou em mudanças sociais efetivas e que, de certo modo, implodiram alguns dos valores de uma sociedade racista, com sério perfil escravagista e preconceituoso.

A ação política dos acadêmicos iniciou uma espécie de sistema de defesa das culturas de diáspora, que se estenderam pelo século XX e início do século XXI. Se hoje testemunhamos movimentos de resistência como CEDENPA - Centro de Defesa do Negro no Pará, Federação Espírita Umbandista e dos Cultos Afro Brasileiros do Pará, a música de uma Gaby Amarantos, as batalhas de poesia oral das periferias, os rolezinhos dos grupos de Rap e Hip Hop, assomados à ação criativa dos demais poetas da negritude (Nazareno Tourinho, Alfredo Garcia-Bragança, Raimundo Sodré, Carlos Correia Santos, Paloma Franca Amorim, por exemplo), deva-se, além da sensibilidade, da consciência e do engajamento de seus integrantes, à fértil semeadura que a Academia do Peixe Frito deixou em nossa vivência social.

A APF, no entanto, deve ser entendida como uma organização emblemática, espécie de referência deste sistema de valorização diaspórico-africana, que teve como precursor, ainda no século XIX, Os Serões da Mãe Preta, coletânea didática de autoria do escritor nativista Juvenal Tavares, publicada durante o Romantismo paraense, e segue até, por exemplo, a crônica de um expert como Raimundo Sodré, os versos de poetas como Pelé do Manifesto, Ruth Clark, confluídos com os estudos fundacionais de Vicente Salles (talvez o último, tardio e decisivo, "integrante" da Academia) e o seu O Negro no Pará sob o regime da escravidão, e demais estudos minuciosamente executados por este sábio paraense.

Daí é que não poderíamos encerrar de deixar aqui nosso mais intenso reconhecimento a Tó Teixeira, Bruno de Menezes, De Campos Ribeiro, Jaques Flores, Abguar Bastos, Dalcídio Jurandir, Nunes Pereira, Rodrigues Pinajé, Paulo de Oliveira, Vicente Salles, Paulo de Oliveira, Sandoval Lage, Ernani Vieira, Muniz Barreto, Arlindo Ribeiro de Castro, Lindolfo Mesquita... Sem a luta destes jornalistas e literatos, certamente não teríamos o protagonismo das gentes das periferias (os arrabaldes de então), o povo preto que dá à nossa cultura um ritmo e colorido singular. Sem a Academia do Peixe Frito, é fato, nosso presente seria o de subtrair as vozes e tonalidades das gentes que foram arrastadas à América pelos grilhões violência e que aqui, associados aos descendentes dos Tupinambá, resistiram, graças aos marcos simbólicos, de sua fé, de sua literatura, enfim, de suas culturas. Axé aos peixefritanos de ontem, de hoje; viva os de sempre: os de luta.

\section{REFERÊNCIAS}

https://cidades.ibge.gov.br/brasil/pa/belem/historico

COELHO, Marinilce Oliveira. Memórias literárias de Belém do Pará: o Grupo dos Novos, 1946-1952. Campinas, 2003.

BRITO, Lenora Menezes de. “Academia do Peixe Frito”, In: GALLINDO, Afonso. O Negro no Pará: 50 anos depois. Vídeo documentário, dirigido por Afonso Gallindo, Belém, Instituto de Artes do Pará, 2005.

FLORES, Jaques. Panela de Barro. 2 ed. col: Lendo o Pará [org. Vicente Salles]. Fundação Cultural do Pará, Belém, 1990.

FIGUEIREDO, Aldrin Moura de. Eternos modernos: uma história social da arte e da literatura na Amazônia, 1908-1929. Tese (Doutorado em História Social). Instituto de Filosofia e Ciências Humanas. Unicamp, Campinas, 2001.

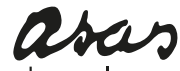

da palavra 
FIGUEIREDO, Aldrin Moura de. De pincéis e letras: Os manifestos literários e visuais no modernismo amazônico na Década de 1920. Revista Territórios \& Fronteiras, Cuiabá, v. 9, n. 2, jul.-dez. 2016.

FURTADO, Marli Tereza. Universo derruido e corrosão do herói em Dalcídio Jurandir. Campinas: Mercado de Letras, 2010.

JACOB, Célia (org.) Asas da Palavra, revista da graduação em Letras da Universidade da Amazônia; diversos números que abrangem Brun ode Menezes e Dalcídio Jurandir.

LEAL, Luiz Augusto Pinheiro. Gladiadores de Escassa Musculatura. Belém, IAP, 2013.

NUNES, Benedito; PEREIRA, Ruy. PEREIRA, Soraia. Dalcídio Jurandir: o romancista da Amazônia. Rio de Janeiro e Belém, FCRB/SECULT-PA/, 2006.

NUNES, Paulo; COSTA, Vânia. Academia do Peixe Frito: diálogos e intersecções entre Literatura, jornalismo e Ciências Sociais na Amazônia do século XX. $40^{\circ}$ Encontro Anual da ANPOCS. Anais..., Caxambu, out. 2016. Disponível em: <http://www.anpocs.com/index. $\mathrm{php} /$ papers-40-encontro/st-10/st02-8/10533-academia-do-peixe-frito-dialogos-e-interseccoes-entre-literatura-jornalismo-e-ciencias-sociais-na-amazonia-do-seculo-xx/file >. Acesso em: 10 jan. 2018.

NUNES, Paulo. Útero de Areia, um estudo do romance 'Belém do Grão-Pará', de Dalcidio Jurandir. Tese de Doutorado. Disponíbvel em: http://www.biblioteca.pucminas.br/teses/Letras_NunesPJ_1.pdf

Recebido em 02 Jun 2018 | Aprovado em 27 Jun 2018

Paulo NUNES

Doutor em Letras - Literaturas em Língua Portuguesa - pela Pontifícia Universidade Católica de Minas Gerais. É professor titular da Universidade da Amazônia, onde atua na graduação em Letras, mestrado e doutorado em Comunicação, Linguagens e Cultura da UNAMA. É um dos coordenadores do Grupo de Estudos interinstitucionais (UNAMA/UFPA) Narramazônia: narrativas contemporâneas da Amazônia Paraense, e um dos coordenadores do projeto de Pesquisa Academia do Peixe Frito: interfaces jornalismo e literatura. E-mail: pontedogalo3@gmail.com

\section{Vânia Torres COSTA}

Doutora em Comunicação pela Universidade Federal Fluminense (UFF), Atualmente é professora adjunta e vice-coordenadora da Faculdade de Comunicação da Universidade Federal do Pará (UFPA), onde coordena o projeto 'Estrada de Ferro Belém-Bragança: sujeitos, memórias e interações comunicacionais na Amazônia paraense'. É uma das coordenadoras do projeto Narramazônia - grupo de estudos e pesquisas sobre Narrativas Contemporâneas na Amazônia Paraense - parceria entre UNAMA (PPGCLC) E UFPA (PPGCOM). Coordena o projeto de Pesquisa Academia do Peixe Frito, que discute Literatura, jornalismo e Negritude no Pará (UFPA/UNAMA). 